\title{
IGUALDADE E VULNERABILIDADES: UMA PROPOSTA DE INTERPRETAÇÃO DO DIREITO FUNDAMENTAL À REPARAÇÃO POR DANOS À LUZ DO LIBERALISMO IGUALITÁRIO
}

\section{Daniel Silva Fampa ${ }^{1}$}

\section{João Daniel Macedo Sá}

Resumo: Este trabalho objetiva compreender as implicações que o princípio da igualdade tem no remodelamento da responsabilidade civil, tendo em vista as transições de paradigmas impulsionadas pela Constituição de 1988. A metodologia do trabalho baseou-se em pesquisa teórica, com levantamento bibliográfico. Para argumentar sobre as hipóteses, utilizou-se o método dedutivo. Neste sentido, examina a conjugação entre liberdades e igualdade, materializando-a na formulação das teorias da justiça de John Rawls e Amartya Sen. Reflete sobre a manifestação de seus pressupostos no Brasil, para se ocupar, finalmente, de uma análise das possibilidades de contemplar a responsabilidade civil como sistema de tutela de vulneráveis.

\section{EQUALITY AND VULNERABILITIES: A PROPOSAL FOR A INTERPRETATION OF THE FUNDAMENTAL RIGHT TO REPARATION FOR DAMAGES IN THE LIGHT OF EGALITARIAN LIBERALISM}

Palavras-chave: Responsabilidade Civil. Igualdade. Liberalismo Igualitário. Dignidade da Pessoa Humana. Vulnerabilidades.

\begin{abstract}
This work aims to understand the implications of the principle of equality in civil liability's reshaping, in view of the transitions of paradigms that happened since Brazilian Constitution of 1988. The work was based on theoretical research, with a bibliographical survey, using the deductive method. In this sense, it examines the conjugation between liberties and equality, materializing it in the formulation of the justice theories of John Rawls and Amartya Sen. It also reflects on the manifestation of its presuppositions in Brazil, to analyze, finally, the possibilities of contemplating civil liability as a system of guardianship of the vulnerable ones.
\end{abstract}

Keywords: Civil Liability. Equality. Egalitarian Liberalism. Human Person's Dignity. Vulnerabilities.

\footnotetext{
${ }^{1}$ Mestrando em Direito pelo Programa de Pós-Graduação em Direito da Universidade Federal do Pará (PPGD/UFPA), sob a orientação da Prof. ${ }^{a}$ Dr. ${ }^{a}$ Pastora do Socorro Teixeira Leal. Bacharel em Direito pela mesma instituição. Bolsista da Coordenação de Aperfeiçoamento de Pessoal de Nível Superior (CAPES). Advogado. E-mail: danielsfampa@gmail.com.

2 Doutor em Direito pelo Programa de Pós-Graduação em Direito da Universidade Federal do Pará (PPGD/UFPA), tendo sido Bolsista da Coordenação de Aperfeiçoamento de Pessoal de Nível Superior (CAPES). Atualmente é professor Adjunto da UFPA, e advogado. E-mail: joaosa@ufpa.br
} 


\section{CONSIDERAÇÕES INICIAIS}

A Constituição Federal vigente alçou o direito à reparação por danos a bens materiais e imateriais à condição de direito fundamental (art. $5^{\circ}$, inciso $\mathrm{V}^{3}$ ), dando à figura da responsabilidade civil status constitucional, sendo considerada esta uma das maiores mudanças provocadas pela da incidência das normas constitucionais da Carta de 5 de outubro de 1988 no âmbito das relações privadas.

Sendo isto considerado um dos grandes fenômenos sociojurídicos da contemporaneidade (LEAL, 2014, p. 461), é de se reconhecer que tal acontecimento não ocorreu de modo indiscriminado e aleatório por parte do legislador constituinte, mas sim busca atender um ideal de justiça consideravelmente importante na ordem constitucional brasileira: o de construir uma sociedade livre, justa e solidária (CF, art. $3^{\circ}$, inciso I).

$\mathrm{Na}$ verdade, para além das discussões referentes às possibilidades de alocação da responsabilidade civil como categoria imbricada com modelos de justiça distintos (justiça comutativa, justiça corretiva e justiça distributiva $)^{4}$, busca-se, com este trabalho, estabelecer uma linha argumentativa a partir da filosofia política, em especial no que tange ao liberalismo de princípios de Rawls e Sen, capaz de demonstrar o substrato igualitário que compõe o direito fundamental à reparação por danos.

Isto porque um dos grandes dilemas que marca o debate contemporâneo entre os teóricos da filosofia política refere-se à ideal distribuição de liberdades e da igualdade no plano das sociedades contemporâneas, questionando-se em que medida uma pode ou não ser restringida em nome da salvaguarda da outra, bem como em que circunstâncias seria possível conciliá-las dentro de uma proposta que satisfaça as exigências da justiça.

Por conta disto, ao se discutir tais perspectivas a partir do dissenso teórico e filosófico entre John Rawls e Amartya Sen, será possível verificar de que maneiras conceitos como liberdade, igualdade e vulnerabilidade possuem participação direta na necessidade de redimensionar o paradigma de pensamento que sustenta as categorias que formam o sistema de reparação civil.

\footnotetext{
${ }^{3}$ Art. $5^{\circ}$ Todos são iguais perante a lei, sem distinção de qualquer natureza, garantindo-se aos brasileiros e aos estrangeiros residentes no País a inviolabilidade do direito à vida, à liberdade, à igualdade, à segurança e à propriedade, nos termos seguintes: V - é assegurado o direito de resposta, proporcional ao agravo, além da indenização por dano material, moral ou à imagem;

${ }^{4}$ A este respeito, vale a leitura de DRESCH, Rafael de Freitas Valle. Fundamentos do direito privado: uma teoria da justiça e da dignidade humana. São Paulo: Atlas, 2013.
} 
Este trabalho objetiva compreender as implicações que o princípio da igualdade tem no remodelamento da interpretação da responsabilidade civil, tendo em vista as transições de paradigmas que vêm ocorrendo neste patamar a partir da Constituição de 1988.

A metodologia do trabalho baseou-se em pesquisa teórica, com levantamento bibliográfico. Para justificar e argumentar sobre as hipóteses levantadas foi utilizado o método dedutivo.

O trabalho se desenvolve em seis capítulos, sendo o capítulo 2 dedicado à discussão sobre o aparente conflito entre liberdades e igualdade e sua respectiva relação de interdependência. No capítulo 3 são apresentadas questões ligadas conjugação de liberdade e igualdade e o acesso a bens primários no âmbito do liberalismo igualitário. O capítulo 4 trata da proteção à pessoa humana e da eficácia horizontal dos direitos fundamentais. E o capítulo 5 discute a responsabilidade civil como ferramenta de concretização da tutela da pessoa humana.

\section{2 É POSSÍVEL SER LIVRE SEM SER IGUAL?}

Muito se reflete, atualmente, sobre o que significa a igualdade para o direito, contemplada em nossa Constituição Federal no caput do artigo $5^{\circ}$ como um bem a ser garantido a todos, tendo em vista a premissa básica de que a dinâmica social brasileira contemporânea aponta para um arranjo de profundas desigualdades do ponto de vista socioeconômico e político, sendo indispensável repensar a efetivação deste direito fundamental nas relações do Estado com os indivíduos e destes entre si, almejando uma sociedade mais justa, livre e, ao mesmo tempo, solidária (CF, art. $3^{\circ}$, inciso I).

Embora o axioma da igualdade tenha sido insculpido no conteúdo formal das constituições brasileiras desde a Constituição Imperial de 1824, o que se vislumbra, na realidade, é o reforço cotidiano de práticas nocivas aos anseios de isonomia e de justiça social, podendo-se constatar, a partir do próprio exemplo da pioneira das constituições, a coexistência da normativa constitucional da igualdade com a permissividade do regime escravocrata, demonstrando o abismo existente entre a mera previsão legal e a efetivação deste ideal político (ROCHA, 1996, p. 288). 
Este debate, acerca de como dar matiz à igualdade em um contexto jurídico, guarda intrínseca relação com a maneira por meio da qual ocorre a distribuição de bens e direitos aos indivíduos em um determinado corpo social, sendo certo que, ao mesmo tempo em que tal distribuição pode consolidar o discrímen negativo de indivíduos naturalmente detentores de um acesso reduzido a bens, esta também pode constituir-se em um mecanismo de redução das desigualdades, de modo a buscar garantir o máximo equilíbrio social possível, sem que se viole liberdades consideradas essenciais para o desenvolvimento dos projetos de vida individuais.

Ressalte-se que a igualdade que aqui está sendo tratada não se refere a uma perspectiva fática ou cultural, mas sim aquela do ponto de vista jurídico-político, isto é, uma igualdade de tratamento perante a lei e em prol da progressiva redução de fatores de desigualdade socioeconômica, pois o direito à igualdade deve caminhar lado a lado com o reconhecimento da diferença, que se opera a partir da necessidade de compreensão do espaço social como cenário possível para a manifestação de diferentes modos de vida e convívio comunitário.

Aliás, o balanceamento entre o reconhecimento da igualdade jurídica e o reconhecimento da diferença, nos termos acima propostos, representa, de acordo com Boaventura de Sousa Santos (SANTOS e CHAUI, 2013, p. 78), uma das maiores tensões contemporâneas referentes aos direitos humanos, realizando o autor a seguinte formulação no intuito de representar a distinção: “temos o direito a ser iguais quando a diferença nos inferioriza e temos o direito a ser diferentes quando a igualdade nos trivializa” (SANTOS e CHAUI, 2013, p. 79).

A partir deste contexto, em que crescem as demandas por igualdade em multivariadas perspectivas ${ }^{5}$, surge como questionamento relevante a possibilidade de um indivíduo ser considerado livre sem que seja igual aos demais membros do corpo social no qual está inserido, o que parece, de plano, intuitivamente inviável, a depender do uso que se atribua aos ideais da liberdade e da igualdade.

\footnotetext{
${ }^{5}$ Em sua obra Desigualdade reexaminada, o filósofo e economista Amartya Sen inicia a discussão sobre o lugar da igualdade no cenário social com a pergunta "igualdade de quê?”, fazendo referência à diversidade de contendas historicamente percebidas em nome deste ideal, cada qual com a aspiração à igualdade de um respectivo bem ou recurso, de acordo com as necessidades dos indivíduos da época, dentre as quais se podem vislumbrar, e.g., os clamores utilitaristas (igualdade no peso das utilidades), os brados libertários (igualdade com respeito a uma classe inteira de direitos e liberdades), os igualitaristas de renda (igualdade na distribuição de renda) etc (SEN, 2001, p. 21).
} 
Neste sentido, sendo reconhecida a condição de vulnerabilidade de determinados indivíduos ou grupos sociais, isto é, sua condição de inferioridade lato sensu em comparação com os demais, torna-se necessária sua discriminação positiva, ou seja, a realização de políticas no intuito de buscar garantir o maior equilíbrio possível entre pessoas de perfis socioeconômicos diferenciados, a fim de "acelerar o processo de tornar a sociedade mais igualitária” (WARBUTON, 1998, p. 112 apud DIAS e SOARES, 2014, p. 44).

Este processo vem sendo desenvolvido, em especial, a partir da promulgação da Constituição de 1988, com a adoção de diversos mecanismos de discrímen positivo - como é o caso das ações afirmativas, que representam, na essência, a ideia de discriminação positiva , bem como com a previsão normativa de garantias próprias a indivíduos considerados vulneráveis em diversos sistemas, estas últimas detalhadas com mais rigor em momento posterior do presente trabalho.

Ademais, cumpre asseverar que a Filosofia Política não permaneceu alheia à constatação de ser impossível almejar a incolumidade das liberdades individuais sem que estas fossem acompanhadas pela busca por igualdade em diferentes frentes políticas, razão pela qual são diversas a concepções de justiça distributiva consideradas igualitárias, justamente por se ocuparem do tema da repartição de bens e recursos entre os indivíduos sem descurarem de apresentar um modelo de distribuição que possa ser considerado o mais igualitário possível, sem que isto viole de modo ilegítimo as liberdades necessárias para o desenvolvimento dos projetos de vida.

Neste cenário, cabe analisar, com atenção singular, o conjunto de pressupostos teóricos e filosóficos que forma o pensamento de alguns dos principais desenvolvedores do chamado liberalismo igualitário ou liberalismo de princípios, por se tratar de uma tradição de pensamento das mais preocupadas em conciliar liberdades e igualdade de modo apropriado no âmbito da filosofia política.

Assim, busca-se, no decorrer da seção a seguir, compreender em particular as bases do pensamento de John Rawls na formulação de sua teoria denominada "justiça como equidade”, assim como as importantes críticas feitas por Amartya Sen a suas premissas basilares, o que resulta como indispensável para a posterior compreensão das alternativas de tutela da pessoa nas relações privadas. 


\section{A CONJUGAÇÃo DE LIBERDAdE E IGUALDAdE E O ACESSO A BENS PRIMÁRIOS NO ÂMBITO DO LIBERALISMO IGUALITÁRIO: A CRÍTICA DE SEN AO PENSAMENTO RAWLSIANO}

Como já ressaltado, os autores alinhados ao pensamento liberal igualitário buscaram, em suas obras, o desenvolvimento ou o aperfeiçoamento de teorias sob o mote central do elemento da igualdade enquanto ideal orientador necessário na distribuição de bens aos indivíduos, por entenderem que as demais concepções políticas desconsideravam este elemento em suas premissas, ou mesmo situavam-na em patamar secundário.

Inserido neste contexto, está a teoria da justiça como equidade de John Rawls, um dos maiores nomes da filosofia política contemporânea, publicada originalmente no ano de 1971, em obra intitulada "Uma Teoria da Justiça”. Na referida obra, o autor tem como um de seus principais objetivos conceber os princípios de justiça - a saber, o princípio da liberdade igual e o princípio da diferença - a serem levados em consideração na tarefa de distribuição de bens desempenhada pelas instituições, bem como analisar possíveis argumentos a favor de sua escolha.

Para tanto, Rawls desenvolve um mecanismo artificial o qual ele mesmo denomina "véu da ignorância”, afirmando que os participantes da sociedade em que vigorarão os princípios da justiça estarão por detrás do referido véu no momento da escolha, desconhecendo sua virtual posição socioeconômica no momento em que o véu for retirado, de modo a evitar que os princípios sejam escolhidos com a finalidade de propiciar o autofavorecimento e a proteção de interesses egoístas.

Além disso, constata-se que, para o sucesso na utilização deste mecanismo, o modelo de sociedade deve atender a algumas condicionantes que são chamadas pelo autor de circunstâncias da justiça, as quais podem ser resumidas, em essência, no conflito de interesses e na escassez moderada, assim definidos por ele:

[...] Há conflito de interesses porque ninguém é indiferente com relação a como são distribuídos os maiores benefícios produzidos pela cooperação, pois, para perseguir seus objetivos, cada qual prefere uma fatia maior a uma fatia menor desses benefícios.

[...] há a condição de escassez moderada entendida de modo que abranja uma ampla gama de situações. Os recursos não são tão abundantes a ponto de que os esquemas de cooperação se tornem supérfluos, nem são as condições tão

Revista Brasileira de Direito Civil em Perspectiva | e-ISSN: 2526-0243 | Maranhão | v. 3 | n. 2 | p. 23 - 43 | Jul/Dez. 2017. 
difíceis a ponto de condenarem empreendimentos proveitosos ao fracasso inevitável (RAWLS, 2008, p. 153-154).

Em outras palavras, muito embora o próprio autor pontue que “a cooperação social viabiliza para todos uma vida melhor do que qualquer um teria se tentasse viver apenas por seus próprios esforços” (RAWLS, 2008, p. 153), a existência de reivindicações conflitantes na distribuição de bens e no respeito a convicções de cunho religioso e filosófico impõe o reconhecimento de que cada indivíduo quer ter para si a maior quantidade possível dos recursos necessários para o desenvolvimento de seu plano de vida, pois, por conta da escassez moderada, a distribuição não pode ser feita de modo a contemplar integralmente as exigências de cada um.

É válido ressaltar que a base das expectativas dos participantes da comunidade, isto é, o objeto de distribuição por parte das instituições, são apenas os bens primários do tipo social, isto é, direitos, liberdades, oportunidades, renda e riqueza (RAWLS, 2008, p. 110), não entrando na distribuição os bens primários naturais (provenientes da loteria natural), tais como os atributos físicos dos indivíduos, seus talentos e seu nível de suscetibilidade a enfermidades, por não ser possível sua distribuição por parte das instituições, cabendo a elas tão somente realizar a distribuição de modo a minimizar as discrepâncias relativas aos bens primários sociais.

Precisamente neste ponto é que reside uma notável crítica de Amartya Sen à compreensão de Rawls na formulação de sua teoria da justiça, pois o filósofo e economista indiano sustenta sua contestação, dentre outras assertivas a serem oportunamente tratadas mais adiante, na consideração de que "uma proposta igualitária aceitável não deveria se concentrar na igualdade de bens primários” (GARGARELLA, 2008, p. 72).

O que importa, por ora, é compreender o que representam exatamente estes bens na teoria rawlsiana. E, neste desiderato, devemos ter em conta que tanto os bens primários naturais quanto os do tipo social são almejados pelos indivíduos para compor sua respectiva fatia de recursos disponíveis, e que tais bens são utilizados como os meios necessários para a busca de cada projeto de vida, de modo que, “com uma quantidade maior desses bens, em geral é possível prever um maior êxito na realização das próprias intenções e na promoção dos próprios objetivos, sejam quais forem esses objetivos” (RAWLS, 2008, p. 110). 
Portanto, os bens primários do ideário rawlsiano não constituem a noção de bemestar tal como desenvolvida, por exemplo, pelo utilitarismo, referente à realização plena dos objetivos associados ao projeto de vida individual elaborado, mas sim representam as condições necessárias para que cada um busque realizar este projeto, independentemente, $a$ priori, de qual seja ele (GARGARELLA, 2008, p. 23).

É dizer que, quanto mais um indivíduo disponha de direitos, oportunidades, renda, aptidão psicofísica etc, mais capaz ele será de executar com sucesso as ações que o levem a atingir um estado de autorrealização que conduza à concretização de seu plano racional, o que soa como algo intuitivamente dedutível ao se examinar qualquer modelo de sociedade existente, atendendo às circunstâncias da justiça de Rawls ou não.

Conclusivamente, neste particular, Rawls sustenta que, de posse das informações referentes à natureza dos bens primários a serem distribuídos e limitados pelas circunstâncias da justiça, os participantes da posição original escolheriam como princípios da justiça (a) o princípio da liberdade igual e (b) o princípio da diferença, sobre os quais são formuladas as seguintes definições:

[...] Primeiro: cada pessoa deve ter um direito igual ao sistema mais extenso de iguais liberdades fundamentais que seja compatível com um sistema similar de liberdades para as outras pessoas.

Segundo: as desigualdades sociais e econômicas devem estar dispostas de tal modo que tanto (a) se possa razoavelmente esperar que se estabeleçam em benefício de todos como (b) estejam vinculadas a cargos e posições acessíveis a todos (RAWLS, 2008, p. 73).

Feitas estas considerações, cabe frisar que, não obstante a teoria da justiça como equidade seja considerada um marco no redimensionamento das discussões referentes à justiça distributiva, seus pressupostos teóricos e filosóficos foram alvos de ataques de diversas frentes de pensamento, por alguns que não a consideravam como suficientemente liberal - tal como o libertário Robert Nozick em Anarquia, Estado e Utopia (1974) - e por outros que a achavam insatisfatoriamente igualitária.

Ínsito neste último rol está Amartya Sen, que, ao longo do desenvolvimento de obras importantes quanto ao exame do estado das desigualdades políticas e socioeconômicas de impacto global, teceu críticas pertinentes à teoria de Rawls, sendo uma delas merecedora de uma análise um pouco mais pormenorizada, por abordar problemas procedimentais que são referentes à tutela dos vulneráveis em países como o Brasil, e que guarda relação com a já 
referida objeção à utilização dos bens primários do tipo social como critério único de satisfação de uma distribuição equilibrada dos recursos.

Antes disso, contudo, é válido ressaltar que o objetivo de Sen com este e outros óbices firmados não é o de desqualificar o trabalho de Rawls na formulação de seus postulados, mas sim o de fornecer um aparato teórico e filosófico capaz de produzir melhoramentos na teoria da justiça como equidade, uma vez que se considera "haver certo consenso na ideia de que, assim como as propostas de 'bem-estar' defendiam uma medida igualitária 'subjetiva' demais, a medida proposta por Rawls corre o risco de ser 'objetiva' demais” (GARGARELLA, 2008, p. 76).

Dito isto, cumpre iniciar o tratamento da objeção de Sen, ressaltando que esta tem como motivação central a inferência do autor de que não são apenas os bens primários do tipo social que interferem decisivamente na capacidade dos indivíduos em converter os bens em liberdades, mas que também a quantidade que cada um possui de recursos do tipo natural influi (ou deveria influir) no modo como as instituições operam a distribuição, de modo que "a igualdade de parcelas de bens primários ou de recursos pode seguir lado a lado com sérias desigualdades nas liberdades reais desfrutadas por diferentes pessoas” (SEN, 2001, p. 136).

Neste sentido, o autor adota uma categoria conceitual no intuito de demonstrar uma possível falha no mecanismo de distribuição de bens rawlsiano, especialmente no que se refere a este elemento da base das expectativas - bens primários do tipo social -; para ele (2001, p. 141), há de se ter em conta que os indivíduos apresentam variações em seu potencial (ability) para a conversão dos recursos (ou bens primários) em efetivas liberdades substantivas, isto é, dois indivíduos que hipoteticamente possuam o mesmo pacote de bens primários, inclusive nas mesmas quantidades, podem apresentar drásticas distinções em traços naturais como sexo, idade, dotes genéticos, que propiciam uma desigualdade profunda no nível de liberdades substantivas para a realização de seus respectivos projetos de vida.

Assim, podemos pensar em um exemplo que o próprio Sen utiliza para demonstrar a relevância de sua crítica, o qual consiste na constatação de dois indivíduos que possuem quantidades diferentes de bens primários do tipo social, sendo que A possui mais bens desta categoria do que B, o que faria Rawls concluir, a partir de sua teoria, que B é menos favorecido em relação a A e aos demais que possuem mais bens primários sociais, e que, 
portanto, em decorrência do princípio da diferença, B deve extrair mais benefícios das desigualdades sociais e econômicas do que A.

Em contrapartida, porém, verifica-se, no mesmo exemplo, que A possui algum tipo de deficiência que reduz substancialmente sua capacidade de conversão (ability), impedindo-o de utilizar seus recursos com a mesma eficiência que B para transformá-los em liberdades substantivas efetivas e executar com sucesso seu projeto racional de vida, o que demonstra que, na prática, ainda que A possua mais bens primários sociais (renda, riqueza, direitos, oportunidades etc) do que $\mathrm{B}$, poderá ser considerado menos favorecido e, portanto, mais vulnerável, demandando um conjunto maior de elementos de proteção do sistema de distribuição de bens e direitos.

A crítica de Sen, ressalte-se, não serve apenas para mostrar que alguém teoricamente mais favorecido, levando-se em conta apenas a perspectiva dos bens sociais, seja potencialmente menos favorecido e mais vulnerável do que um concidadão, tal como no exemplo apresentado, mas serve também, e acima de tudo, para impor a conclusão de que a desvantagem em relação aos bens sociais pode ser agravada sobremaneira pela escassez também de bens naturais, tal como define o autor:

[...] Similarmente, ao lidar com a pobreza em países mais ricos, temos de considerar o fato de que muitos daqueles que são pobres em termos de renda e outros bens primários também têm características - idade, deficiências, propensão a doenças etc. - que lhe dificultam a conversão de bens primários em capacidades básicas, p. ex., ser capaz de se locomover, levar uma vida saudável, tomar parte na vida da comunidade. Nem os bens primários, nem os recursos, definidos de modo abrangente, podem representar a capacidade que uma pessoa realmente desfruta.

(SEN, 2001, p. 137).

Em linhas gerais, cabe pontuar que a crítica de Sen não invalida todo o árduo esforço metodológico de Rawls para conceber os princípios de justiça e pensar a distribuição de bens primários tendo como base aqueles do tipo social; na realidade, a contribuição de Sen deve ser enxergada como elemento capaz de aprimorar a abordagem rawlsiana, tornando-a mais abrangente e ampliando seus horizontes para outros tipos de vulnerabilidade.

Finda esta discussão sobre as divergências teóricas entre as concepções de dois marcantes liberais igualitários, torna-se possível aventar a existência de dois tipos de vulnerabilidade, os quais, por óbvio, não se excluem, mas podem compor em paralelo o perfil biossocial de um mesmo indivíduo: (a) a vulnerabilidade em perspectiva natural, referente a 
fatores que não são distribuídos por instituições, mas que são adquiridos pela loteria natural e a partir de elementos randômicos, ou seja, sexo, idade, propensão a doenças etc; e (b) a vulnerabilidade socioeconômica, relativa aos bens primários do tipo social que Rawls já destacava em sua teoria da justiça como equidade, tais como direitos, oportunidades, renda, riqueza, dentre outros.

Nesta perspectiva, será o objetivo principal da seção seguinte o exame da proteção a estas duas modalidades de vulneráveis no contexto das relações privadas no Brasil, por meio de uma análise essencialmente do contexto normativo ínsito na ordem política e constitucional brasileira vigente e, portanto, posterior a 1988, a fim de verificar o grau de proteção que se dá aos bens de pessoas vulneráveis neste tipo de relação, em especial no que se refere ao direito à reparação por danos.

\section{A PROTEÇÃO À PESSOA HUMANA E A EFICÁCIA HORIZONTAL DOS DIREITOS FUNDAMENTAIS: QUEM SÃO OS VULNERÁVEIS DE FATO?}

É tarefa das mais difíceis pensar as estruturas normativas contemporâneas de proteção aos interesses e bens jurídicos de indivíduos vulneráveis no Brasil sem que se reflita, em paralelo, sobre o paradigma da vinculação dos particulares ao conteúdo constitucional de proteção à pessoa, isto é, a chamada eficácia horizontal dos direitos fundamentais.

A compreensão deste fenômeno demanda uma leitura historicizada das tradições políticas que marcaram a trajetória do constitucionalismo brasileiro na história recente, em especial em seu período republicano. Nesta esteira, é possível conceber três grandes fases, estritamente conectadas ao que os estudiosos do assunto geralmente concebem como as três principais dimensões dos direitos fundamentais: o paradigma liberal, o paradigma social e o paradigma pós-social ou contemporâneo.

Não constitui objetivo deste trabalho a apresentação das principais características de cada um dos referidos paradigmas, bem como suas distinções e implicações na distribuição de direitos e bens, bastando que se saiba que no contexto dos dois primeiros momentos, não era possível pensar na força normativa dos direitos fundamentais - incluindo-se aí o direito à reparação por danos - frente aos particulares, os quais eram ferramentas de proteção dos 
indivíduos estritamente em face da opressão e da arbitrariedade estatal (CUNHA JÚNIOR, 2013, p. 619).

Todavia, em um dado momento, percebeu-se que as ações estatais representam apenas uma das fontes em potencial de produção de danos à pessoa, e que, na realidade, apontar o foco dos direitos e garantias individuais exclusivamente para o Estado representa a omissão no cuidado de prevenção a outras formas de dano. A este respeito, cabe relembrar algumas das importantes lições de Daniel Sarmento na obra "Direitos Fundamentais e Relações Privadas”:

[...] Do direito espontaneamente produzido nas comunidades carentes até a autorregulação em setores altamente especializados da economia, assiste-se a proliferação de novas fontes normativas fora do aparato estatal, para o desespero do jurista tradicional, que, na linha de Kelsen, insiste em confundir Direito com Estado.

[...]

Contudo, a regulação jurídica emergente destas fontes não estatais não se submete aos mecanismos de legitimação democrática das leis, e opera num espaço nem sempre transparente, muitas vezes impenetrável à fiscalização pela opinião pública. Tal fato aumenta os riscos para os direitos humanos, e expõe o indivíduo a novas formas de opressão, por vezes mais difíceis de enfrentar que a proveniente do próprio Estado.

(grifo nosso)

(SARMENTO, 2004, p. 137).

Por conta disso, paulatinamente foi-se pondo fim à ideia de equilíbrio entre os particulares, que outrora servia de justificativa ao modelo liberal de não intervenção do Estado nas relações entre particulares, nas quais prevalecia o ideal de autonomia privada e a presunção de igualdade entre as partes, razão pela qual se permitia a incidência das normas constitucionais apenas em caráter programático e indireto (SCHREIBER, 2013, p. 12).

O diagnóstico social do Brasil no século XXI aponta para um cenário que se distancia amplamente de qualquer noção de igualdade nas relações privadas, pelo quê se reacende a discussão sobre a tutela de indivíduos considerados vulneráveis. Se pararmos para analisar a conjuntura normativa atual de nossa ordem constitucional vigente, será possível verificar a existência de múltiplos diplomas e dispositivos destinados à tutela especial de grupos ou pessoas tradicionalmente considerados vulneráveis, ou cuja condição tenha sido reconhecida no plano normativo há relativamente pouco tempo (e.g., o consumidor), seja em relações entre particulares ou não. 
É o caso, por exemplo, da proteção às crianças e adolescentes, na forma da Lei ${ }^{0}$ 8.069/1990 (Estatuto da Criança e do Adolescente); ou da proteção especial às pessoas com deficiência realizada por meio dos dispositivos da Lei no 13.146/2015 (Estatuto da Pessoa com Deficiência); ou, ainda, de indivíduos considerados vulneráveis não pela carência de bens primários do tipo natural (sexo, idade etc), mas sim pelo reduzido acesso a direitos, oportunidades e outros bens primários sociais, como os consumidores (Lei nº 8.078/1990 Código de Defesa do Consumidor) e os trabalhadores (dispositivos variados da Consolidação das Leis do Trabalho e em diversas normas regulamentadoras existentes).

É preciso atentar para a curiosa evidência de que, muito embora a defesa de Sen aos bens primários do tipo natural e a respectiva necessidade de pensar na correção da teoria da justiça como equidade tenham vindo em momento substancialmente posterior aos estudos originais de Rawls e seu esforço em conceber um mecanismo de justiça procedimental pura capaz de salvaguardar os bens primários sociais, é possível perceber que, ao menos na tradição jurídica de nosso país, a preocupação com a proteção a vulneráveis em perspectiva natural pode ser considerada mais efetiva do que aqueles considerados inferiores em patamares relativos a bens sociais, o que talvez ocorra por conta de uma maior facilidade de perceber aqueles em relação a estes ${ }^{6}$. Esta hipótese possui um peso argumentativo forte e merece uma justificação mais detalhada.

Afirma-se isto por conta de alguns pressupostos referentes ao status quo das relações sociais que apenas vêm sendo notabilizados há relativamente pouco tempo e aceitos como

\footnotetext{
${ }^{6}$ Diz-se isto com apoio na premissa do uso de mecanismos de ação afirmativa voltados especialmente à tutela de vulneráveis em sentido de bens naturais, o que é realizado em menor grau no intuito de proteção de vulneráveis em bens sociais. Isto pode ser verificado no acesso a vagas de universidade e concursos, onde é diversificada a previsão de vagas especialmente destinadas a negros (vide <http://www.stf.jus.br/portal/cms/verNoticiaDetalhe.asp?idConteudo=287577> - Concurso para cargos efetivos no STF e no CNJ terá reserva de $20 \%$ das vagas para negros), pessoas com deficiência, membros de comunidades indígenas e quilombolas etc, ao passo em que a proteção de vulneráveis em sentido social, categoria na qual usualmente se consideram as pessoas de baixa renda ou aqueles que concluíram o ensino médio em escola pública, apenas ocorre no acesso ao ensino superior, sabendo-se que em concursos públicos não relativos ao ingresso no ensino superior, a tentativa de equiparação, por exemplo, de membros das camadas menos favorecidas economicamente ocorre exclusivamente por meio da isenção de taxas de inscrição e afins, sendo certo que a vantagem na preparação para o certame por parte daqueles que possuem mais recursos financeiros é evidente, indo de encontro à lógica de equilíbrio que deveria prevalecer. Fique claro que não se está propugnando que estes vulneráveis em sentido social deveriam também ter um acesso diferenciado às vagas em concursos públicos, mas apenas se questiona o que justifica o grau inferior de proteção nesta esfera em relação àqueles que possuem vulnerabilidades em termos de bens primários naturais, quando a proteção deveria ser na justa medida para ambos os grupos de pessoas.
} 
válidos em momento mais recente ainda. Trata-se da constatação de que vivemos em sociedades de massa, a partir da solidificação da presença da escassez no acesso a bens e de uma apropriação das técnicas apenas pelos grupos hegemônicos da sociedade (SANTOS, 2015, p. 21 e 25); em outras palavras, a percepção de que a globalização não cumpriu suas promessas e de que é notável o surgimento de novos tipos de desigualdade, chegando a se falar em uma pobreza estrutural, caracterizada justamente pela "ausência deliberada do Estado de sua missão social de regulação” (SANTOS, 2015, p. 72), elemento marcante em sociedades que ainda não atentaram completamente para a nocividade que possui o poder privado.

Além disso, para além de se perceber um arranjo social marcado pela massificação, é possível afirmar que vivemos em uma sociedade na qual “a produção social de riqueza é acompanhada sistematicamente pela produção social de riscos” (BECK, 2011, p. 23), estes que surgem de modo intrinsecamente imbricado com os conflitos típicos das sociedades em que prevalece a escassez (BECK, 2011, p. 25).

Aliás, há quem afirme, como Ulrick Beck, que estes riscos não surgem ao acaso como fenômenos não intencionais do processo de globalização e de desenfreado desenvolvimento de setores da atividade econômica competitiva, sendo, na realidade, um grande negócio (big business), ou, em suas palavras, “as necessidades insaciáveis que os economistas sempre procuraram” (2011, p. 25 e 28).

Observados os caracteres que compõem nosso status quo das relações sociais e do modelo de distribuição de riscos, impõe-se uma última observação a fim de se chegar à conclusão desta seção. Trata-se do reconhecimento de que a vulnerabilidade em relação a bens primários do tipo social não existe em abstrato, mas apenas pode assim ser considerada se observada em uma relação jurídica concreta.

Isto porque, ao contrário do que ocorre no tocante às vulnerabilidades referentes a bens primários naturais, nas quais o acesso reduzido a tais bens implica na presunção do reconhecimento deste caráter de inferioridade prima facie aos respectivos indivíduos, no caso dos vulneráveis em relação a bens do tipo social, esta vulnerabilidade apenas existirá em um modelo específico de relação, não ostentando o indivíduo em questão esta condição para toda a miríade de relações sociais nas quais for parte. 
Pense-se em um indivíduo que exerça suas funções laborais no ofício de extração de minérios e metais preciosos, com a exposição constante a riscos à saúde e à vida e sua reconhecida vulnerabilidade perante seu empregador, que detém o controle da produção e o poder diretivo sobre seu tempo e espaço no transcurso de suas atividades diárias; este mesmo trabalhador, não obstante sua vulnerabilidade seja patente no caso de sua relação laboral, não poderá assim ser considerado no que for referente às relações familiares em que figurar, podendo e devendo, ainda, exercer um poder diretivo em relação aos filhos, à luz dos deveres de criação e assistência impostos pelo artigo 229 da Constituição Federal ${ }^{7}$ e pelo artigo 1.634, inciso I do Código Civil brasileiro ${ }^{8}$.

Desta forma, percebe-se que, quando a vulnerabilidade for aquela ligada ao menor acesso a bens do tipo social, tratar-se-á de uma espécie em que tal condição prevalece essencialmente de modo flutuante, relacionada estritamente a um modelo de relação social no qual figure aquele indivíduo, em que seja possível aferir peremptoriamente sua condição de vulnerável e merecedor de uma tutela especial a seus bens jurídicos.

Portanto, prevalecendo no estado de coisas do paradigma pós-social a percepção de que a totalidade dos indivíduos está exposta a uma multiplicidade de danos em potencial, em sua maioria, ressalte-se, vinculados à atividade econômica desempenhada por meio do poder privado e de seus grandes conglomerados corporativos, é possível reconhecer, neste plano, uma vulnerabilidade de certo modo universal, havida por todas as vítimas de danos, em especial os danos a bens imateriais, como se verá em seguida, o que justifica a existência de um sistema de proteção especial à pessoa neste particular.

Dito isto, pretende-se, na seção final, analisar as possibilidades de se contemplar a responsabilidade civil como este sistema, com vistas ao objetivo imediato de efetivação do direito fundamental à reparação por danos e ao fim mediato de concretização do princípio da dignidade da pessoa humana, fundamento dos mais importantes de nossa república.

\section{A RESPONSABILIDADE CIVIL COMO FERRAMENTA DE CONCRETIZAÇÃO DA TUTELA DA PESSOA HUMANA}

\footnotetext{
${ }^{7}$ Art. 229: "Os pais têm o dever de assistir, criar e educar os filhos menores, e os filhos maiores têm o dever de ajudar e amparar os pais na velhice, carência ou enfermidade”.

${ }^{8}$ Art. 1.634: "Compete a ambos os pais, qualquer que seja a sua situação conjugal, o pleno exercício do poder familiar, que consiste em, quanto aos filhos: I - dirigir-lhes a criação e a educação”;
} 
Embora a reparação por danos, usualmente chamada de responsabilidade civil, fosse prevista expressamente no art. 159 do Código Civil de $1916^{9}$, sua utilização ocorria estritamente em relação à ocorrência de danos a bens materiais, tendo em vista o caráter patrimonialista sobre o qual se assentava o regramento da época sobre as relações privadas.

Trata-se de um período no qual Código Civil e Constituição não dialogavam, prevalecendo para o Código a função de "Constituição do homem comum” (LÔBO, 1999, p. 99), e incidindo a Constituição Federal nas relações privadas apenas de modo programático e indireto, dirigida apenas ao legislador infraconstitucional (SCHREIBER, 2013, p. 12), sem, contudo, que seu conteúdo fosse vinculante para os particulares.

Esta realidade apresentava diversos problemas para a proteção da pessoa humana, especialmente pela perspectiva de que havia uma igualdade entre os particulares e de que, por conta disso, o Estado não deveria preocupar-se em regular estas relações; os problemas surgidos desta omissão, ressalte-se, já foram oportunamente tratados na seção anterior.

Todavia, a partir da promulgação da Carta Magna de 5 de outubro de 1988, a proteção ao patrimônio foi relativizada, ganhando importância a projeção da pessoa humana como finalidade última do ordenamento jurídico, em decorrência da dignidade da pessoa humana, um dos fundamentos da república (CF, art. $1^{\circ}$, inc. III). Isto não representa propriamente "que a proteção dispensada pelo direito ao patrimônio se perca e se esvazie em retóricas digressões sobre o ser humano como tal” (CORTIANO JÚNIOR, 2002, p. 156), mas sim que se deve situar o patrimônio como ferramenta voltada para a garantia dos bens básicos dos indivíduos, em caráter meramente instrumental.

Não obstante o avanço havido em termos normativos referentes à proteção do direito à reparação por danos, inclusive em âmbito constitucional (CF, art. 5º, inciso V), e que se caracteriza também pela utilização de diversas normas de textura aberta, de modo a facilitar a adequação da norma à conjuntura social em que está inserida, bem como com a expressa previsão da reparação por danos a bens imateriais de forma autônoma em relação ao dano material, algo impensado até antes de 1988, diversos problemas remanescem em relação à aplicação dos institutos e categorias da responsabilidade civil e de sua utilização como

\footnotetext{
${ }^{9}$ Dizia o dispositivo em questão: “Aquele que, por ação ou omissão voluntária, negligência, ou imprudência, violar direito, ou causar prejuízo a outrem, fica obrigado a reparar o dano”.
} 
ferramenta de concretização dos direitos da pessoa, o que pode ser explicado por algumas razões.

A primeira delas é a persistência de uma mentalidade patrimonialista no que se refere à aplicação das normas referentes à matéria, descurando-se de interpretar as hipóteses de dano de modo compatível com o conteúdo axiológico do texto constitucional. Muito embora a responsabilidade civil tenha deixado de ser considerada como mera categoria contida no estudo do direito das obrigações após o advento do Código Civil de 2002 - a despeito do que ocorria no Código Civil de 1916 -, é possível perceber a grande resistência a uma interpretação personalista de institutos variados, como é o caso do dano moral, frequentemente interpretado de maneira muito discrepante entre cortes e juízos singulares.

A segunda grande razão guarda relação de causa e efeito com a primeira, mas com ela não se confunde: trata-se da percepção de que, por conta das amarras impostas ao intérprete pelos paradigmas ainda existentes do (a) patrimonialismo codificador e da (b) igualdade entre os particulares, a responsabilidade civil ainda não é satisfatoriamente utilizada enquanto mecanismo capaz de reduzir o status de vulnerabilidade que ostentam as vítimas de dano.

Um elemento que comprova esta assertiva é a relativização apenas recente do ônus imposto às vítimas de terem de comprovar a ocorrência de culpa por parte do agente causador do dano para que fossem reparadas ou compensadas pelo respectivo agravo, rompendo com o paradigma clássico da culpa como pressuposto necessário para a configuração do dever de reparar.

A previsão de uma responsabilidade sem culpa - ou responsabilidade objetiva -, embora existente em legislações esparsas anteriores à nova ordem constitucional (tais como a Política Nacional do Meio Ambiente e o Decreto das Estradas de Ferro - no 2.681/1912), apenas veio a ser incluída em uma cláusula geral por meio do artigo 927, parágrafo único do Código Civil de $2002^{10}$, o que não significa, por si só, a solução de todos os problemas de imputação às vítimas deste ônus por vezes diabólico, mas, ao menos, reduz as vítimas sem um efetivo direito à reparação.

\footnotetext{
${ }^{10}$ Art. 927, parágrafo único - Haverá obrigação de reparar o dano, independentemente de culpa, nos casos especificados em lei, ou quando a atividade normalmente desenvolvida pelo autor do dano implicar, por sua natureza, risco para os direitos de outrem.
} 
Isto porque, em diversos casos, a dificuldade de produção probatória, comumente associada à ausência de recursos para custeio destes, representa "negativa do direito à respectiva indenização ou recomposição pela violação de sua esfera jurídica” (LEAL, 2014, p. $463)^{11}$.

Cabe ressaltar que estes elementos são problemáticos particularmente na ocorrência de danos a bens imateriais da pessoa, pois sua violação é o que geralmente pressupõe a afronta à dignidade da pessoa humana, tendo em vista que uma das teorias ${ }^{12}$ que busca conceituar o que seria o dano moral ampara suas pretensões nos danos injustos a estes bens e, por consequência, na lesão à dignidade das vítimas.

Assim sendo, é factível compreender o sistema de responsabilidade civil enquanto um sistema de tutela especial da pessoa, porquanto se situe no papel de garantidor da salvaguarda de bens jurídicos essencialmente ligados à concepção de dignidade da pessoa humana, corolário central da ordem constitucional brasileira.

Entretanto, para fazer cumprir este desiderato teleológico, torna-se imperioso interpretá-la e examinar suas categorias e seus pressupostos de modo a assegurar uma tutela que leve em conta o estado de vulnerabilidade das vítimas de dano, sendo este estado associado à contemplação das circunstâncias fáticas que compõem o arranjo socioeconômico da realidade brasileira, no qual a inferência de que há uma miríade de danos oriundos das atividades do poder privado exige especial proteção da pessoa nessas relações.

\section{CONSIDERAÇÕES FINAIS}

A discussão sobre a igualdade no acesso a bens primários, sejam eles do tipo natural ou social, representa um marco de pensamento relevante para a reflexão de para quais indivíduos e em quais circunstâncias é possível presumir a vulnerabilidade no contexto das relações jurídicas e, consequentemente, da necessidade de distribuição de bens, direitos e oportunidades de modo a assegurar o maior equilíbrio social possível.

\footnotetext{
11 Apesar da visualização destes problemas, vale pontuar que a legislação já vem sendo adotada no intuito de majorar a proteção a vulneráveis nesta perspectiva, como é o caso da previsão de inversão do ônus da prova como um dos direitos básicos dos consumidores (CDC, art. $6^{\circ}$, inc. VIII), pelo que, na verdade, se questiona, dentre outros elementos, o ritmo demasiadamente prolongado com o qual se processam estas alterações no modo de pensar os danos à pessoa.

12 Neste sentido, BODIN DE MORAES, Maria Celina. Danos à pessoa humana: uma leitura civil-constitucional dos danos morais. Rio de Janeiro: Renovar, 2003, p. 85/132-133.
} 
Nesta esteira, é de se reconhecer a inconsistência do paradigma clássico da igualdade entre os particulares, o que impunha uma interpretação de desnecessidade de regulação destas relações por parte do Estado, responsável por potencializar a omissão em face de danos diversos à pessoa humana, compreendida como vulnerável neste tipo de relação.

Assim, partindo do pressuposto da necessidade de interpretar o conteúdo do direito fundamental à reparação por danos à luz do preceito constitucional da igualdade, é possível compreender algumas das recentes transformações havidas em matéria de responsabilidade civil, não sendo despiciente que se ponha suas categorias jurídicas a serviço da tutela da pessoa humana, a qual, circunstanciando-se em uma posição de vítima de danos, encontra-se em patamar de vulnerabilidade em face das ameaças e efetivas lesões a seus bens imateriais.

Portanto, é possível concluir que a lógica de proteção a indivíduos vulneráveis e de potencialização de seu acesso aos bens primários se constitui em justificativa para o status constitucional e fundamental do direito à reparação por danos, reforçando as exigências de tutela destes bens e de interesses jurídicos correlatos. 


\section{REFERÊNCIAS}

BECK, Ulrich. Sociedade de risco: rumo a uma outra modernidade. Trad.: Sebastião Nascimento. São Paulo: Editora 34, 2011.

BRASIL. Constituição da República Federativa do Brasil, de 05 de outubro de 1988. Diário Oficial da União. Brasília, 1988. Disponível em: <http://www.planalto.gov.br/ccivil_03/constituicao/constituicaocompilado.htm>. Acesso em: 12 dez. 2016.

. Lei $n^{0}$ 3.071/1916, de $1^{\circ}$ de janeiro de 1916. Diário Oficial da União. Brasília, 1916. Disponível em: <https://www.planalto.gov.br/ccivil_03/leis/L3071impressao.htm>. Acesso em: 16 dez. 2016.

. Lei ${ }^{0}$ 10.406/2002, de 10 de janeiro de 2002. Diário Oficial da União. Brasília, 2002. Disponível em: <http://www.planalto.gov.br/ccivil_03/leis/2002/l10406.htm>. Acesso em: 16 dez. 2016.

CONCURSO para cargos efetivos no STF e no CNJ terá reserva de 20\% das vagas para negros. Portal do Supremo Tribunal Federal, Brasília, 18 mar. 2015. Disponível em: $<$ http://www.stf.jus.br/portal/cms/verNoticiaDetalhe.asp?idConteudo=287577>. Acesso em: 16 dez. 2016.

CORTIANO JÚNIOR, Eroulths. Para além das coisas: breve ensaio sobre o direito, a pessoa e o patrimônio mínimo. In: RAMOS, Carmem Lúcia Silveira et al (org.). Diálogos sobre Direito Civil. Rio de Janeiro: Renovar, 2002.

CUNHA JÚNIOR, Dirley. Curso de Direito Constitucional. 7. ed. Salvador: Juspodivm, 2013.

DIAS, Paula Regina Pereira dos Santos Marques; SOARES; Zilmar Timoteo. O sistema especial de proteção dos direitos humanos: a busca pela igualdade e o respeito à diferença. Revista Iniciação Científica CESUMAR. Maringá, v. 16, n. 1, jan./jun. 2014, p. 41-52.

GARGARELLA, Roberto. As teorias da justiça depois de Rawls: um breve manual de filosofia política. Trad.: Alonso Reis Freire. São Paulo: Martins Fontes, 2008.

LEAL, Pastora do Socorro Teixeira. Responsabilidade Civil: inovações normativas, desafios e perspectivas. In: (Org.) Direito Civil Constitucional e outros estudos em homenagem ao Prof. Zeno Veloso: uma visão luso-brasileira. São Paulo: Atlas, 2014.

LÔBO, Paulo. Constitucionalização Do Direito Civil. Revista de Informação Legislativa, Brasília, v. 36, n. 141, jan./mar. 1999, p. 99-109. Disponível em: < http://www2.senado.leg.br/bdsf/item/id/453>. Acesso em: 16 dez. 2016.

RAWLS, John. Uma Teoria da Justiça. Trad.: Álvaro de Vita. 3. ed. São Paulo: Martins Fontes, 2008.

ROCHA, Carmen Lucia Antunes. Ação afirmativa: o conteúdo democrático do princípio da igualdade jurídica. Revista de Informação Legislativa. Brasília, n. 131, jul./set. 1996, p. 
283-295. Disponível em: < http://www2.senado.leg.br/bdsf/item/id/176462>. Acesso em: 13 dez. 2016.

SANTOS, Boaventura de Sousa; CHAUI, Marilena. Direitos Humanos, Democracia e Desenvolvimento. São Paulo: Cortez Editora, 2013.

SANTOS, Milton. Por uma outra globalização: do pensamento único à consciência universal. 24. ed. Rio de Janeiro: Record, 2015.

SARMENTO, Daniel. Direitos Fundamentais e Relações Privadas. Rio de Janeiro: Lumen Juris, 2004.

SCHREIBER, Anderson. Direito Civil e Constituição. São Paulo: Atlas, 2013.

SEN, Amartya. Desigualdade Reexaminada. Trad.: Ricardo Doninelli Mendes. Rio de Janeiro: Record, 2001. 